\title{
Sex of the baby and risk of gestational diabetes mellitus in the mother: a systematic review and meta-analysis
}

\author{
Diana Jaskolka ${ }^{1}$ - Ravi Retnakaran ${ }^{1,2,3,4}$ - Bernard Zinman ${ }^{1,2,3,4}$. \\ Caroline K. Kramer ${ }^{1,2,3}$
}

Received: 28 June 2015 / Accepted: 22 July 2015 / Published online: 8 August 2015

(C) Springer-Verlag Berlin Heidelberg 2015

\begin{abstract}
Aims/hypothesis It has recently emerged that carrying a male fetus may be associated with poorer maternal beta cell function and an increased risk of gestational diabetes mellitus (GDM). Recognising that the overall impact of fetal sex on maternal glucose metabolism is likely to be subtle, we sought to perform a systematic review and meta-analysis of observational studies to obtain a robust estimate of the incremental maternal risk of GDM associated with the sex of the baby. Methods We searched PubMed and EMBASE to identify observational studies published between 1 January 1950 and 4 April 2015 that reported data on fetal sex and the prevalence of GDM. Two independent reviewers extracted the data and pooled estimates of the RR were calculated by a randomeffects model. We considered male fetus as the exposure and prevalence of GDM as the outcome of interest.

Results We identified 320 studies through electronic searches and nine studies through manual searches. Twenty studies met
\end{abstract}

Electronic supplementary material The online version of this article (doi:10.1007/s00125-015-3726-1) contains peer-reviewed but unedited supplementary material, which is available to authorised users.

Caroline K. Kramer

ckramer@mtsinai.on.ca

1 Department of Medicine, University of Toronto, Toronto, ON, Canada

2 Division of Endocrinology, University of Toronto, Toronto, ON, Canada

3 Leadership Sinai Centre for Diabetes, Mount Sinai Hospital, 60 Murray Street, Suite L5-029, Mailbox-21, Toronto, ON, Canada M5T 3L9

4 Lunenfeld-Tanenbaum Research Institute, Mount Sinai Hospital, Toronto, ON, Canada the inclusion criteria, yielding data on 2,402,643 women. Pooled analysis of these studies demonstrated an increased risk of GDM in women carrying a male fetus compared with women carrying a female fetus (RR 1.04; 95\% CI 1.02, 1.06). This result was confirmed in a sensitivity analysis including only studies that applied a stringent definition of GDM (RR 1.03; 95\% CI 1.01, 1.06) $\left(I^{2}=0 \%, p=0.66\right)$.

Conclusions/interpretation Pregnant women carrying a boy have a $4 \%$ higher relative risk of GDM than those carrying a girl. The fetus thus may have previously unsuspected effects on maternal glucose metabolism in pregnancy.

Keywords Beta cell function · Fetal sex · Gestational diabetes $\cdot$ Male fetus $\cdot$ Meta-analysis $\cdot$ Systematic review

\section{Abbreviations \\ GDM Gestational diabetes mellitus \\ NOS Newcastle-Ottawa scale}

\section{Introduction}

The sex of a baby has been associated with the risk of adverse obstetrical outcomes at delivery. Indeed, carrying a male fetus confers increased risks of multiple adverse perinatal outcomes including premature rupture of membranes, pre-term delivery, failure to progress in the first and second stages of labour, nonreassuring fetal heart rate patterns, umbilical cord prolapse, true umbilical cord knot, Caesarean delivery and lower Apgar scores $[1,2]$. However, it has traditionally not been suspected that the sex of the fetus could hold implications for maternal glucose metabolism.

Intriguingly, it was recently demonstrated that, when compared with those carrying a girl, women carrying a male fetus 
have poorer pancreatic beta cell function in pregnancy, higher postprandial glycaemia and an elevated risk of gestational diabetes mellitus (GDM), independently of classical diabetes risk factors [3]. Furthermore, in women who develop GDM, the sex of the baby is a predictor of the mother's risk for early postpartum progression to type 2 diabetes after delivery [4]. Since the overall impact of fetal sex on maternal glucose metabolism is likely to be subtle, we reasoned that individual studies might not accurately estimate such a risk compared with comprehensive evaluation across multiple studies. Thus, we have conducted a systematic review and meta-analysis of observational studies to obtain a robust estimate of the incremental maternal risk of GDM associated with the sex of the baby.

\section{Methods}

Data sources and searches This systematic review and metaanalysis is reported in accordance with the Meta-Analysis of Observational Studies in Epidemiology guidelines [5] and is registered with the International Prospective Register of Systematic Reviews (PROSPERO, CRD42015017114). The researchers are experienced in meta-analysis studies [6-9].

We selected relevant studies published between 1 January 1950 and 4 April 2015 by searching Embase and PubMed databases. The following combined text and medical subject heading (MESH) terms were used: 'gestational diabetes' and 'fetal sex'. All potentially eligible studies were considered for review, regardless of the primary outcome or language. A manual search was also performed to include additional relevant articles, using the reference lists of key articles published in English.

Study selection Studies were considered eligible for inclusion if they presented original data for retrospective or prospective observational studies and reported fetal sex ratios for GDM. As diagnostic criteria for GDM can differ by jurisdiction, all definitions were included in this meta-analysis. Studies were excluded if there was no control group of women without GDM or if the study was restricted to specific patient populations (such as pre-term delivery, Caesarean delivery or multiple gestations only). Studies were also excluded if the diseasespecific fetal sex ratio could not be determined due to combined outcomes in which GDM was combined with pregestational diabetes (i.e. women with pre-existing diabetes were not included in the analysis).

Data extraction and quality assessment Two independent investigators (DJ, RR) reviewed study titles and abstracts. Studies that satisfied the inclusion criteria were retrieved for full text evaluation. Studies selected for detailed analysis by these two investigators had an agreement value $(\mathrm{K})$ of $96 \%$.
Extracted data included clinical characteristics (ethnicity, length of gestation, pre-pregnancy BMI) and fetal sex ratio in women with and without GDM. In studies that reported data for both pre-term and term pregnancies or singleton and multiple-gestation pregnancies, data for pre-term and multiple-gestation pregnancies were excluded, if they were extractable. We emailed the authors of included studies with missing descriptive data and authors of excluded studies that we felt potentially may have an unpublished fetal sex ratio. We received many responses that provided additional descriptive data, while no new information on fetal sex ratios was received.

The Newcastle-Ottawa scale (NOS) was applied to assess the quality of the studies included in the meta-analysis [10] (electronic supplementary material [ESM] Table 1). This scale contains four items under the selection domain, one item under the comparability domain and three items under the outcome domain. A star system is used to enable semiquantitative assessment of study quality such that the highest quality studies are awarded one star per item, with the exception of the comparability domain in which the maximum score is two stars for its single item. As such, the NOS ranges from zero to nine stars [11].

Data synthesis and analysis An overall RR was calculated to determine the risk for GDM among women carrying a male fetus in comparison with those carrying a female fetus. We calculated pooled estimates of the RR by using a randomeffects model (DerSimonian-Laird method) to adequately account for the additional uncertainty associated with studystudy variability. The Cochran $Q$ test was used to evaluate heterogeneity between studies and a threshold $p$ value $<0.1$ was considered as statistically significant [12].

We explored heterogeneity between studies using two strategies. First, we re-ran the meta-analyses, removing each study one at a time to determine whether a particular study accounted for the heterogeneity. Then, in light of the variability of the diagnostic protocols and criteria that have been applied for identifying GDM in practice, we performed sensitivity analyses to evaluate the subgroup of studies that had the most stringent approaches to the diagnosis of GDM and so should therefore be the most likely to yield valid estimates. Specifically, we limited this sensitivity analysis to studies that applied the two-step approach to the diagnosis GDM (i.e. screening test followed by a diagnostic OGTT).

The possibility of publication bias was evaluated using a contour-enhanced funnel plot of effect size against the standard error for each trial. Funnel plot asymmetry was evaluated by Begg's and Egger's tests, with significant publication bias defined as a $p$ value $<0.1$. The trim-and-fill computation was used to estimate the effect of publication bias [13]. All statistical analyses were performed using Stata software, version 11.0 (Stata Corporation, College Station, TX, USA). 


\section{Results}

We identified 320 studies through electronic searches and nine studies through manual searches (Fig. 1). Of these, 263 were excluded on the basis of title and abstract, leaving 66 studies for full text evaluation. Based on the full text, a further 46 studies were excluded, 32 of which did not fulfil the inclusion criteria (i.e. matched the control group by fetal sex, included participants with pre-existing diabetes, had no control group or did not include original data). Thus, there was a total of 20 studies on fetal sex and maternal risk of GDM.

The 20 studies $[1,3,4,14-30]$ that met inclusion criteria provide data on 2,402,643 women. A study from Retnakaran and Shah [4] evaluated the risk for GDM conferred by fetal sex in a first pregnancy and, in those women in whom it was applicable, the analogous risk in a second pregnancy such that, in the pooled analyses, the first and second pregnancies from this study were entered as two separate reports. Table 1 summarises the characteristics of the included studies. The studies were published between 1988 and 2015. Mean pre-pregnancy BMI ranged from $21.40 \mathrm{~kg} / \mathrm{m}^{2}$ to $27.40 \mathrm{~kg} / \mathrm{m}^{2}$ and mean gestational age at delivery ranged from 38.36 weeks to 39.99 weeks. ESM Table 2 shows the assessment of the included studies for possible bias using the Newcastle-Ottawa quality assessment scale for cohort studies. All studies achieved at least five stars, indicating overall general good study quality.

The pooled analysis of these 20 studies $(n=2,402,643)$ demonstrated that women carrying a male fetus were at increased risk for GDM when compared with women carrying a female fetus (RR 1.04; 95\% CI 1.02, 1.06) (Fig. 2). There was significant heterogeneity between estimates $\left(I^{2}=37.2 \%\right.$; $p<0.05$ ) and evidence of publication bias on Egger regression

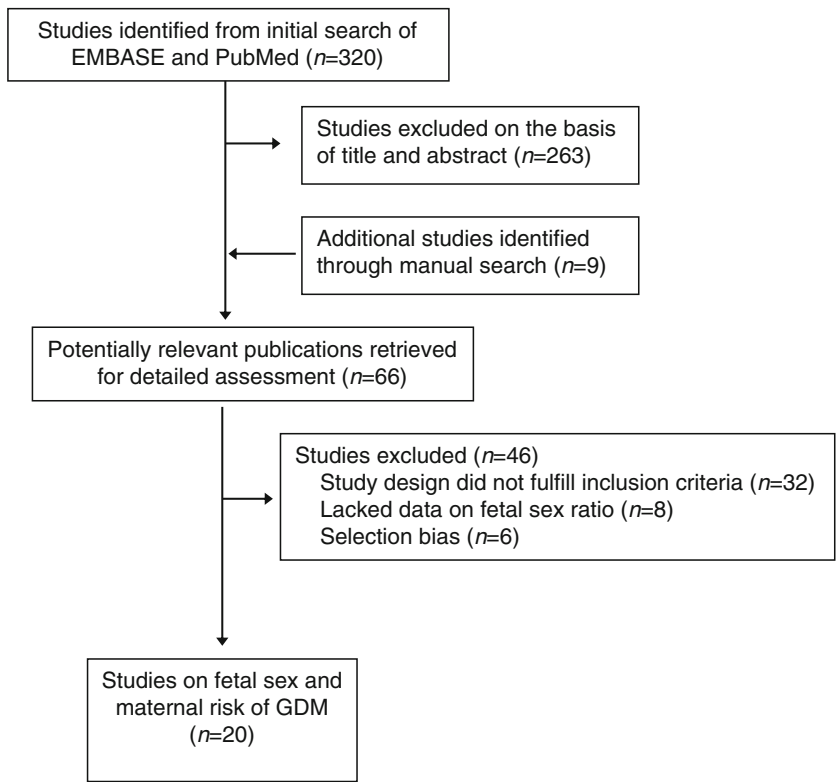

Fig. 1 Flow diagram of search to identify observational studies on fetal sex and maternal risk of GDM test $(p=0.005)$ (ESM Fig. 1). However, the trim-and-fill computation demonstrated that the publication bias did not change the results (RR 1.03; 95\% CI 1.002, 1.07) and a sensitivity analysis including only high-quality reports achieving at least eight stars in the NOS confirmed the results while reducing the publication bias $(p>0.05)$. In addition, our results were unchanged in the following sensitivity analyses: (1) including only the data of first pregnancies from Retnakaran et al [4]; (2) excluding Retnakaran et al [4] from the analysis and (3) including only studies that evaluated more than 10,000 participants $(n=10)$ (data not shown).

We further explored the heterogeneity between studies, performing the steps described earlier. We first re-ran the meta-analysis excluding each study one at a time in order to determine whether a particular study was responsible for the high heterogeneity. Individually, no single study fully explained the heterogeneity. Then, we performed a sensitivity analysis based on the stringency of the diagnostic approach for identifying GDM that was applied in the studies. In this analysis, we included only the seven studies $[1,3,18,25,28-30]$ that used the two-step approach to diagnose GDM (i.e. screening test followed by an OGTT) that was recently recommended by the National Institutes of Health (NIH) Consensus Panel [31]. This analysis confirmed an increased risk for GDM in women carrying a male fetus (RR 1.03; 95\% CI 1.01, 1.06) and eliminated the heterogeneity $\left(I^{2}=0 \%, p=0.66\right)$.

\section{Discussion}

In this study of over 2.4 million pregnancies, we demonstrate that women carrying a male fetus have a $4 \%$ higher relative risk of GDM, when compared with those carrying a girl. While the incremental increase in relative risk is modest in its overall magnitude, it holds implications for our understanding of maternal-fetal physiology. Notably, these data support the emerging concept of a bi-directional maternal-fetal metabolic interplay in which the mother and the fetus each influence the metabolism of the other.

The differential obstetrical risks that have been linked with fetal sex to date are largely events at delivery that clearly involve the fetus in some way (e.g. failure to progress, nonreassuring fetal heart rate patterns, umbilical cord prolapse, Caesarean delivery, lower Apgar scores) [1, 2]. In contrast, GDM is a major maternal medical complication of pregnancy where current understanding of its pathophysiology does not necessarily implicate the fetus as a primary determinant. Specifically, GDM arises in women who have a chronic defect in pancreatic beta cell function that first becomes clinically apparent as an inability to sufficiently increase insulin secretion in response to the metabolic challenge posed by the severe insulin resistance of late pregnancy (resulting in the hyperglycaemia by which GDM is diagnosed) [32]. Although the mechanism 
Table 1 Characteristics of included studies on fetal sex and maternal risk for GDM

\begin{tabular}{|c|c|c|c|c|c|}
\hline Study & $\begin{array}{l}\text { Sample size } \\
\text { (no. of women) }\end{array}$ & Country & Diagnostic criteria for GDM & $\begin{array}{l}\text { Mean pre-pregnancy } \\
\text { BMI }\left(\mathrm{kg} / \mathrm{m}^{2}\right)\end{array}$ & $\begin{array}{l}\text { Mean gestational } \\
\text { age at delivery } \\
\text { (weeks) }\end{array}$ \\
\hline Aibar et al [14] & 29,530 & Spain & NA & NA & 39.21 \\
\hline Breschi et al [15] & 520 & Italy & $\begin{array}{l}\text { Fasting venous blood glucose } \geq 5.5 \mathrm{mmol} / \mathrm{l} \text { and } 2 \mathrm{~h} \text { blood } \\
\quad \text { glucose } \geq 9.2 \mathrm{mmol} / 1\end{array}$ & 22.49 & 39.70 \\
\hline Clausen et al [16] & 309 & Denmark & $\begin{array}{l}\text { Women with risk indicators (family history of diabetes, at least } \\
20 \% \text { pre-pregnancy overweight, previous GDM, previous } \\
\text { delivery of a macrosomic baby }(>4,500 \mathrm{~g} \text { ), and glucosuria) } \\
\text { and two consecutive fasting blood glucose values of at least } \\
\geq 4.1 \mathrm{mmol} \text { were tested by a } 3 \mathrm{~h} 50 \mathrm{~g} \text { OGTT. GDM was } \\
\text { diagnosed if at least two of seven glucose values exceeded } \\
\text { the mean }+3 \mathrm{SD} \text { values for a reference group of normal-weight } \\
\text { non-pregnant women without a family history of diabetes }\end{array}$ & NA & 39.52 \\
\hline Dionne et al [17] & 1,835 & Canada & $\begin{array}{l}2 \mathrm{~h} \text { OGTT value in capillary whole blood of at least } 7.8 \mathrm{mmol} / \mathrm{l} \\
\text { between the } 22 \mathrm{nd} \text { and } 30 \text { th week of gestation }\end{array}$ & NA & 39.05 \\
\hline Ehrlich et al [18] & 250,120 & USA & $\begin{array}{l}50 \mathrm{~g}, 1 \mathrm{~h} \text { glucose challenge test to screen for GDM. If plasma } \\
\text { glucose value } \geq 7.8 \mathrm{mmol} / 1 \text { on the screening test, women went } \\
\text { on to receive a diagnostic } 3 \mathrm{~h}, 100 \mathrm{~g} \text { OGTT. Gestational diabetes } \\
\text { was diagnosed according to the ADA plasma glucose thresholds } \\
\text { for the OGTT, or two or more values meeting or exceeding the } \\
\text { following cut points: fasting glucose } 5.3 \mathrm{mmol} / 1 ; 1 \mathrm{~h} \text { glucose } \\
10.0 \mathrm{mmol} / \mathrm{l} ; 2 \mathrm{~h} \text { glucose } 8.6 \mathrm{mmol} / \mathrm{l} ; 3 \mathrm{~h} \text { glucose } 7.8 \mathrm{mmol} / 1\end{array}$ & NA & 39.09 \\
\hline Gillman et al [19] & 14,881 & USA & $\begin{array}{l}\text { Self-reported GDM: maternal report of diabetes diagnosed by a } \\
\text { doctor during the index pregnancy }\end{array}$ & NA & NA \\
\hline Heckbert et al [20] & 1,278 & USA & Birth certificate report & NA & NA \\
\hline Janssen et al [21] & 17,795 & USA & Birth certificate report & NA & NA \\
\hline Kale et al [22] & 439 & India & $\begin{array}{l}\text { WHO } 1998 \text { criteria - women with impaired glucose tolerance } \\
\text { and with diabetes were considered as having GDM }\end{array}$ & 23.95 & 38.70 \\
\hline Khalil et al [23] & 28,140 & Libya & NA & NA & 39.17 \\
\hline Lawlor et al [24] & 10,179 & UK & Medical records & 22.92 & 39.49 \\
\hline Okereke et al [25] & 78 & USA & $\begin{array}{l}50 \mathrm{~g} \text { OGTT plasma blood glucose } \geq 7.5 \mathrm{mmol} / 1 \text { after } 1 \mathrm{~h} \text {, } \\
\text { followed by abnormality on } 3 \mathrm{~h} \text { OGTT }\end{array}$ & 27.40 & 38.88 \\
\hline Persson et al [26] & 914,167 & Sweden & Medical records & 23.54 & 39.99 \\
\hline Pirkola et al [27] & 4,168 & Finland & $\begin{array}{l}2 \mathrm{~h} 75 \mathrm{~g} \text { OGTT performed after an overnight fast. The upper ranges } \\
\text { of normal capillary blood glucose concentrations in } 1985-1986 \\
\text { were } 5.5,11.0 \text { and } 8.0 \mathrm{mmol} / \mathrm{l} \text { at fasting and at } 1 \mathrm{~h} \text { and } 2 \mathrm{~h} \text { after } \\
\text { the glucose load, respectively. Importantly, diagnosis of GDM } \\
\text { was set after one abnormal value in the OGTT, according } \\
\text { to prevailing national guidelines }\end{array}$ & 21.40 & 39.48 \\
\hline Retnakaran et al [3] & 1,074 & Canada & $\begin{array}{l}50 \mathrm{~g} \text { GCT in late second trimester, followed by referral for } \\
\text { diagnostic OGTT if the GCT was abnormal (blood glucose } \\
\geq 7.8 \mathrm{mmol} / \mathrm{l} \text { at } 1 \mathrm{~h} \text { postchallenge). GDM was diagnosed } \\
\text { based on the OGTT according to NDDG criteria, which require } \\
\text { at least two of the following on the OGTT: fasting blood glucose } \\
>5.8 \mathrm{mmol} / \mathrm{l} ; 1 \mathrm{~h} \text { glucose }>10.6 \mathrm{mmol} / \mathrm{l} ; 2 \mathrm{~h} \mathrm{blood} \text { glucose } \\
>9.2 \mathrm{mmol} / \mathrm{l} \text { or } 3 \mathrm{~h} \text { blood glucose }>8.1 \mathrm{mmol} / \mathrm{l}\end{array}$ & 23.45 & 39.05 \\
\hline Retnakaran et al [4] & $\begin{array}{l}\text { (a) } 642,987 \text { in } \\
\text { first pregnancy } \\
\text { (b) } 366,419 \text { in } \\
\text { second pregnancy }\end{array}$ & Canada & $\begin{array}{l}\text { Provincial administrative databases tracking healthcare provided } \\
\text { in the Canadian province of Ontario }\end{array}$ & NA & NA \\
\hline Ricart et al [28] & 9,270 & Spain & $\begin{array}{l}50 \mathrm{~g} \text { GCT, after which women who had a venous plasma } \\
\text { glucose } \geq 7.8 \mathrm{mmol} / 1 \text { on the GCT were scheduled for a } \\
\text { diagnostic } 100 \mathrm{~g}, 3 \mathrm{~h} \text { OGTT. GDM was defined by two } \\
\text { or more plasma glucose measurements on the OGGT equal to or } \\
\text { exceeding the following NDDG thresholds: fasting, } 5.8 \mathrm{mmol} / \mathrm{l} \text {; } \\
1 \mathrm{~h}, 10.6 \mathrm{mmol} / \mathrm{l} ; 2 \mathrm{~h}, 9.2 \mathrm{mmol} / \mathrm{l} ; 3 \mathrm{~h}, 8.1 \mathrm{mmol} / \mathrm{l}\end{array}$ & 23.95 & 39.50 \\
\hline Sarkar et al [29] & 160 & USA & GDM as per ACOG criteria & NA & 38.36 \\
\hline Sheiner et al [1] & 108,995 & Israel & GDM as per ACOG criteria & NA & 39.18 \\
\hline Xiao et al [30] & 299 & Canada & $\begin{array}{l}\text { GDM was diagnosed according to the ADA's } 2003 \text { diagnostic criteria. } \\
\text { All women underwent a } 50 \mathrm{~g} \text { OGTT at } 24-28 \text { weeks gestation. If the } \\
\text { blood glucose concentration was } \geq 7.8 \mathrm{mmol} / \mathrm{l} \text {, the woman } \\
\text { underwent a } 2 \mathrm{~h} 75 \mathrm{~g} \text { OGTT. GDM was diagnosed if the woman had } \\
\text { two of three blood glucose measurements exceeding the following } \\
\text { thresholds: fasting, } 5.3 \mathrm{mmol} / \mathrm{l} ; 1 \mathrm{~h}, 10.0 \mathrm{mmol} / \mathrm{l} ; 2 \mathrm{~h}, 8.6 \mathrm{mmol} / 1\end{array}$ & 23.81 & 39.05 \\
\hline
\end{tabular}

ACOG, American College of Obstetricians and Gynecologists; GCT, glucose challenge test; NDDG, National Diabetes Data Group 


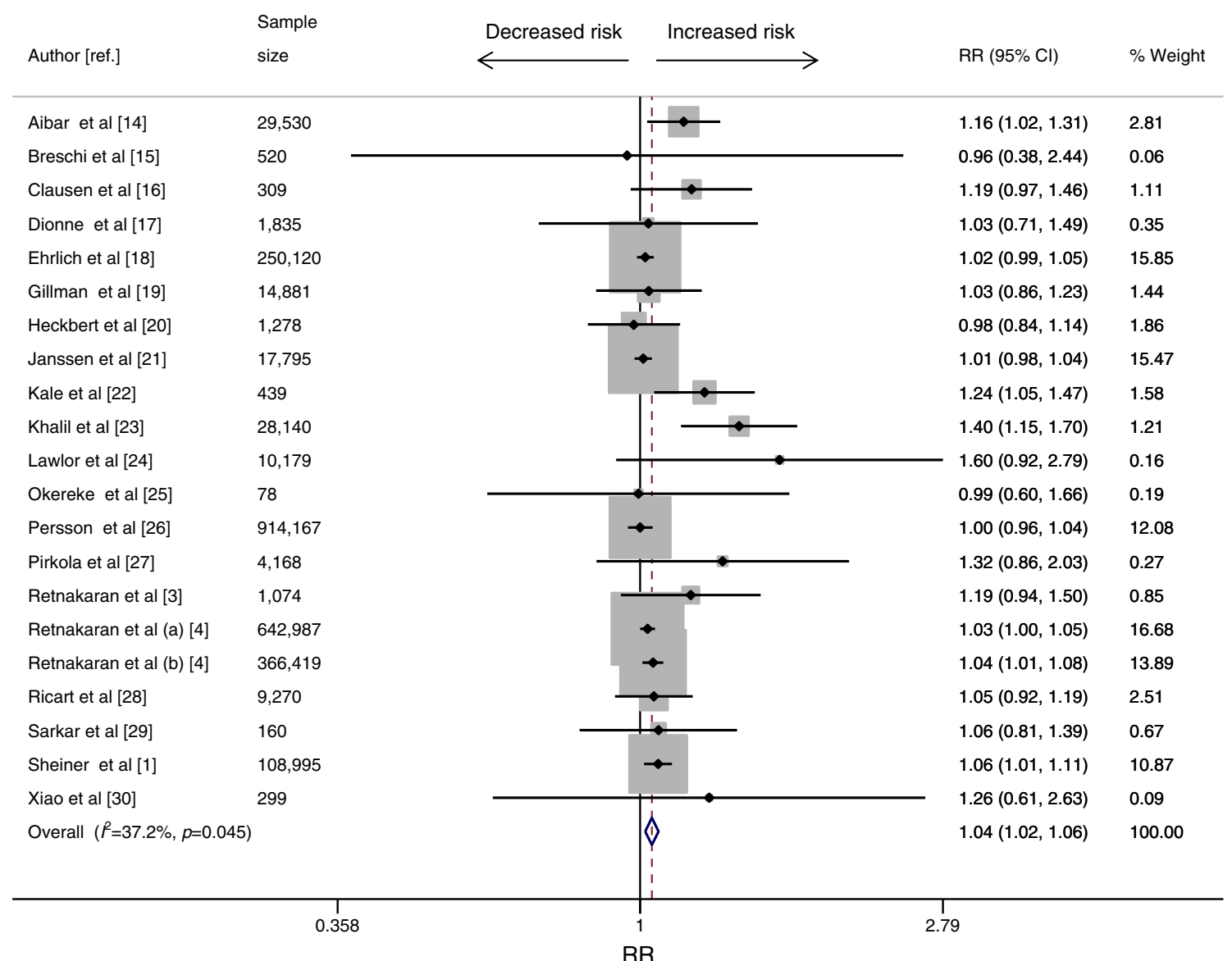

Fig. 2 Meta-analysis of the association in women between carrying a male fetus vs female fetus and the risk of GDM. Weights are from random effects analysis

underlying normal beta cell adaptation has not been fully elucidated, it is believed to involve placentally derived maternal hormones (including human placental lactogens and prolactin) acting through downstream mediators (including the transcription factor FoxMI, the serotonin synthetic enzyme Tph1 and the cell cycle regulator menin), ultimately leading to the expansion of beta cell mass and enhanced insulin secretion [33]. Importantly, it has recently emerged that, after adjustment for classical GDM risk factors (including age, ethnicity, BMI and family history of diabetes), the presence of a male fetus is independently associated with poorer maternal beta cell function [3], thereby providing a potential mechanistic basis through which fetal sex could affect the likelihood of GDM. Another potential explanation for the enhanced risk of maternal GDM conferred by a male fetus could be related to sex-specific selection in utero [34]. As per this hypothesis, our data may indicate that female fetuses are more likely to undergo spontaneous abortion than male fetuses in the presence of poorer prepregnancy beta cell function.

The significance of the link between fetal sex and maternal beta cell function was recently further supported by the observation that the sex of her baby is a predictor of a woman's risk of early postpartum progression to type 2 diabetes after a pregnancy complicated by GDM [4]. Indeed, the beta cell defect that leads to GDM is also responsible for the elevated lifetime risk of type 2 diabetes in affected women [32, 35, 36]. In this context, it is worth noting that women with GDM who deliver a girl have a higher risk of early postpartum progression to type 2 diabetes than those who deliver a boy, potentially reflecting a comparatively poor beta cell function in women who develop GDM while carrying a female fetus (i.e. since their beta cells were unable to compensate appropriately in pregnancy even without the adverse impact of a male fetus) [4]. Thus, fetal sex has implications for maternal risk of diabetes both during pregnancy (as shown in the current analysis) and after delivery.

A strength of this analysis is the large sample size $(>2.4$ million women), which enabled the determination of robust estimates of the maternal risk of GDM. A limitation is that we have pooled unadjusted estimates in this meta-analysis; thus, we did not account for other covariates possibly associated with GDM, such as maternal BMI and age. In this regard, it should be noted that the characteristics of the study populations in most of the studies did not differ when stratified by fetal sex, suggesting that the lack of adjustment for these covariates may be less relevant to our results. Another limitation is the presence 
of publication bias, which potentially could affect our results as there is a lack of published studies demonstrating lesser impact of fetal sex on the prevalence of GDM. However, the trim-andfill computation demonstrated that this potential bias did not affect the results and sensitivity analyses including only highquality reports confirmed our results while reducing the publication bias [37]. Thus, we believe that the publication bias does not mitigate the importance of our results.

The incremental increase in risk of GDM associated with carrying a male fetus is modest in overall magnitude, likely explaining how it has escaped recognition in clinical practice to date. Nevertheless, it could hold practice implications in settings where the screening of pregnant women for GDM is conducted on the basis of clinical risk factors, particularly since interaction has recently been demonstrated between a male fetus and two such factors - maternal age $>35$ years and non-white ethnicity [3]. In addition, in women with GDM, the sex of the baby could contribute to the prediction of maternal risk of early postpartum progression to type 2 diabetes [4]. Even more important are the biologic implications of this relationship, adding to a growing body of evidence supporting the concept of fetal influence on maternal physiology. This evidence base includes the observed genotype-dependent effects of fetal sex on maternal $\mathrm{HbA}_{1 \mathrm{c}}$ at delivery [38] and the recognition that women carrying a fetus with Beckwith-Wiedemann syndrome have a greater than twofold increase in their risk of developing gestational hypertension than when the same mothers carry non-affected siblings [39]. In this context, the current demonstration of an increased risk of GDM when carrying a boy emphasises the emerging concept of a bi-directional metabolic relationship between the mother and the fetus, a perspective that holds fundamental implications for both contemporary understanding and future study of maternal-fetal physiology.

In conclusion, pregnant women carrying a boy have a $4 \%$ higher relative risk of GDM than those carrying a girl. Although the relative risk increment is modest in magnitude, it speaks to an important biological relationship. Specifically, these data suggest that the fetus may have previously unsuspected effects on maternal glucose metabolism in pregnancy and that these effects should be further evaluated in future studies, including those with population registry data.

Contribution statement RR and CKK were responsible for the study concept and design and supervised the study. DJ, RR and CKK acquired the data. Data was analysed and interpreted by all authors. CKK carried out the statistical analyses. DJ wrote the first draft of the manuscript and all authors critically revised the manuscript for important intellectual content. CKK had full access to all of the data in the study and takes responsibility for the integrity of the data and the accuracy of the data analysis. All authors have read and approved the final version of the manuscript.

Duality of interest The authors declare that there is no duality of interest associated with this manuscript.
Funding The study was supported by intramural funds from the Leadership Sinai Centre for Diabetes. The funding source had no role in study design, data collection, data analysis, data interpretation or writing of the report. RR is supported by a Heart and Stroke Foundation of Ontario MidCareer Investigator Award and his research program is supported by an Ontario Ministry of Research and Innovation Early Researcher Award. BZ holds the Sam and Judy Pencer Family Chair in Diabetes Research at Mount Sinai Hospital and University of Toronto.

\section{References}

1. Sheiner E, Levy A, Katz M et al (2004) Gender does matter in perinatal medicine. Fetal Diagn Ther 19:366-369

2. Di Renzo GC, Rosati A, Sarti RD et al (2007) Does fetal sex affect pregnancy outcome? Gend Med 4:19-30

3. Retnakaran R, Kramer CK, Ye C et al (2015) Fetal sex and maternal risk of gestational diabetes mellitus: the impact of having a boy. Diabetes Care 38:844-851

4. Retnakaran R, Shah BR (2015) Fetal sex and the natural history of maternal risk of diabetes during and after pregnancy. J Clin Endocrinol Metab 100:2574-2580

5. Stroup DF, Berlin JA, Morton SC et al (2000) Meta-analysis of observational studies in epidemiology: a proposal for reporting. Meta-analysis Of Observational Studies in Epidemiology (MOOSE) group. JAMA 283:2008-2012

6. Kramer CK, Zinman B, Gross JL et al (2013) Coronary artery calcium score prediction of all cause mortality and cardiovascular events in people with type 2 diabetes: systematic review and metaanalysis. BMJ 346:f1654

7. Kramer CK, Zinman B, Retnakaran R (2013) Short-term intensive insulin therapy in type 2 diabetes mellitus: a systematic review and meta-analysis. Lancet Diabetes Endocrinol 1:28-34

8. Kramer CK, Zinman B, Retnakaran R (2013) Are metabolically healthy overweight and obesity benign conditions?: A systematic review and meta-analysis. Ann Intern Med 159:758-769

9. Eng C, Kramer CK, Zinman B, Retnakaran R (2014) Glucagon-like peptide-1 receptor agonist and basal insulin combination treatment for the management of type 2 diabetes: a systematic review and meta-analysis. Lancet 384:2228-2234

10. Wells GA, Shea B, O'Connell D et al The Newcastle-Ottawa Scale (NOS) for assessing the quality of nonrandomized studies in metaanalyses. Available from www.ohri.ca/programs/clinical epidemiology/oxford.htm. Last accessed 27 July 2015

11. Stang A (2010) Critical evaluation of the Newcastle-Ottawa scale for the assessment of the quality of nonrandomized studies in metaanalyses. Eur J Epidemiol 25:603-605

12. Higgins JP, Thompson SG (2002) Quantifying heterogeneity in a meta-analysis. Stat Med 21:1539-1558

13. Duval S, Tweedie R (2000) Trim and fill: a simple funnel-plotbased method of testing and adjusting for publication bias in meta-analysis. Biometrics 56:455-463

14. Aibar L, Puertas A, Valverde M, Carrillo MP, Montoya F (2012) Fetal sex and perinatal outcomes. J Perinat Med 40:271-276

15. Breschi MC, Seghieri G, Bartolomei G, Gironi A, Baldi S, Ferrannini E (1993) Relation of birthweight to maternal plasma glucose and insulin concentrations during normal pregnancy. Diabetologia 36:1315-1321

16. Clausen TD, Mathiesen ER, Hansen T et al (2009) Overweight and the metabolic syndrome in adult offspring of women with diettreated gestational diabetes mellitus or type 1 diabetes. J Clin Endocrinol Metab 94:2464-2470 
17. Dionne G, Boivin M, Seguin JR, Perusse D, Tremblay RE (2008) Gestational diabetes hinders language development in offspring. Pediatrics 122:e1073-e1079

18. Ehrlich SF, Eskenazi B, Hedderson MM, Ferrara A (2012) Sex ratio variations among the offspring of women with diabetes in pregnancy. Diabet Med 29:e273-e278

19. Gillman MW, Rifas-Shiman S, Berkey CS, Field AE, Colditz GA (2003) Maternal gestational diabetes, birth weight, and adolescent obesity. Pediatrics 111:e221-e226

20. Heckbert SR, Stephens CR, Daling JR (1988) Diabetes in pregnancy: maternal and infant outcome. Paediatr Perinat Epidemiol 2:314-326

21. Janssen PA, Rothman I, Schwartz SM (1996) Congenital malformations in newborns of women with established and gestational diabetes in Washington State, 1984-91. Paediatr Perinat Epidemiol 10:52-63

22. Kale SD, Kulkarni SR, Lubree HG et al (2005) Characteristics of gestational diabetic mothers and their babies in an Indian diabetes clinic. J Assoc Physicians India 53:857-863

23. Khalil MM, Alzahra E (2013) Fetal gender and pregnancy outcomes in Libya: a retrospective study. Libyan J Med 8. doi:10. 3402/ljm.v8i0.20008

24. Lawlor DA, Fraser A, Lindsay RS et al (2010) Association of existing diabetes, gestational diabetes and glycosuria in pregnancy with macrosomia and offspring body mass index, waist and fat mass in later childhood: findings from a prospective pregnancy cohort. Diabetologia 53:89-97

25. Okereke NC, Uvena-Celebrezze J, Hutson-Presley L, Amini SB, Catalano PM (2002) The effect of gender and gestational diabetes mellitus on cord leptin concentration. Am J Obstet Gynecol 187: 798-803

26. Persson M, Fadl H (2014) Perinatal outcome in relation to fetal sex in offspring to mothers with pre-gestational and gestational diabetes - a population-based study. Diabet Med 31:1047-1054

27. Pirkola J, Pouta A, Bloigu A et al (2010) Risks of overweight and abdominal obesity at age 16 years associated with prenatal exposures to maternal prepregnancy overweight and gestational diabetes mellitus. Diabetes Care 33:1115-1121

28. Ricart W, Lopez J, Mozas J et al (2009) Maternal glucose tolerance status influences the risk of macrosomia in male but not in female fetuses. J Epidemiol Community Health 63:64-68
29. Sarkar S, Watman J, Seigel WM, Schaeffer HA (2003) A prospective controlled study of neonatal morbidities in infants born at 36 weeks or more gestation to women with diet-controlled gestational diabetes (GDM-class Al). J Perinatol 23:223-228

30. Xiao L, Zhao JP, Nuyt AM, Fraser WD, Luo ZC (2014) Female fetus is associated with greater maternal insulin resistance in pregnancy. Diabet Med 31:1696-1701

31. Vandorsten JP, Dodson WC, Espeland MA et al (2013) NIH consensus development conference: diagnosing gestational diabetes mellitus. NIH Consens State Sci Statements 29:1-31

32. Retnakaran R (2009) Glucose tolerance status in pregnancy: a window to the future risk of diabetes and cardiovascular disease in young women. Curr Diabetes Rev 5:239-244

33. Angueira AR, Ludvik AE, Reddy TE, Wicksteed B, Lowe WL Jr, Layden BT (2015) New insights into gestational glucose metabolism: lessons learned from 21 st century approaches. Diabetes 64 : 327-334

34. Catalano R, Ahern J, Bruckner T, Anderson E, Saxton K (2009) Gender-specific selection in utero among contemporary human birth cohorts. Paediatr Perinat Epidemiol 23:273-278

35. Retnakaran R, Qi Y, Sermer M, Connelly PW, Hanley AJ, Zinman B (2010) Beta-cell function declines within the first year postpartum in women with recent glucose intolerance in pregnancy. Diabetes Care 33:1798-1804

36. Kramer CK, Swaminathan B, Hanley AJ et al (2014) Each degree of glucose intolerance in pregnancy predicts distinct trajectories of beta-cell function, insulin sensitivity, and glycemia in the first 3 years postpartum. Diabetes Care 37:3262-3269

37. Sterne JA, Egger M, Smith GD (2001) Investigating and dealing with publication and other biases in meta analysis. BMJ 323: 101-105

38. Hocher B, Schlemm L, Haumann H et al (2010) Interaction of maternal peroxisome proliferator-activated receptor gamma2 Pro12Ala polymorphism with fetal sex affects maternal glycemic control during pregnancy. Pharmacogenet Genomics 20: 139-142

39. Wangler MF, Chang AS, Moley KH, Feinberg AP, Debaun MR (2005) Factors associated with preterm delivery in mothers of children with Beckwith-Wiedemann syndrome: a case cohort study from the BWS registry. Am J Med Genet A 134A:187-191 